\title{
Psychological treatment for personality disorders
}

\author{
Anthony W. Bateman \& Peter Tyrer
}

Abstract There is encouraging evidence that some patients with personality disorder are treatable. Psychotherapeutic interventions show promise, although interpretation of the literature is problematic: the number of patients in most trials is small, outcome measures are questionable, follow-up is limited, and treatments are multifaceted, complex interventions in which the effective components are unclear. The evidence base can be assessed according to efficacy and generalisability, and when both are taken into account the best verification is for psychodynamic therapy. However, there is inadequate evidence to make specific recommendations for any particular therapy.

This is the first of three articles by Anthony Bateman and Peter Tyrer on personality disorders. The second (Tyrer \& Bateman, 2004), which reviews drug treatments, also appears in this issue of APT. The third, on service delivery for people with personality disorders (Bateman \& Tyrer, 2004), will be published in the next issue.

Personality disorder is common and rarely treated in its own right, although interest in the subject is growing and, with it, a demand for effective treatments. This demand has not been met adequately but there has been a significant shift from the view that personality disorder is untreatable; we do have treatments that have at least some efficacy and this article describes the evidence base for these. However, the treatment of personality disorder is not just the simple application of therapy: the planning and management of treatment is at least equally important. This is the subject of a further article.

\section{What treatments are available and how do we determine their success?}

Although it is common for every known treatment to be used at some time for conditions that are deemed untreatable, almost all of the psychotherapeutic interventions for personality disorder that carry some elements of respectability are listed in Table 1. Each of these will be discussed in turn. In discussing the efficacy of treatments for personality disorder, we have to be aware of the special problems associated with assessment of these conditions:

- the high level of comorbidity with other disorders of both personality and mental state (Tyrer et al, 1997);

- the fluctuating nature of personality status over time, mainly as a consequence of concomitant mood changes (Clark et al, 2003);

- the need to have a long period of observation, preferably at least a year, before a treatment can be said to be properly evaluated;

- the recognition that personality disorder is a multifaceted condition that can be influenced in many different ways and fully justifies the use of what are now described as 'complex interventions' (Campbell et al, 2000) to treat it. Complex interventions lead to complex evaluations and consequent greater difficulty in interpreting results.

The other important distinction in determining the value of an intervention is whether this has been demonstrated in standard practice or under strict experimental conditions. This distinction was first highlighted by Schwarz \& Lellouch (1967) in discussing differences between randomised trials,

Anthony Bateman is Clinical Head and Research Lead of Psychotherapy Services at the Halliwick Unit, St Ann's Hospital (St Ann's Road, London N15 3TH, UK. Tel: 0208442 6093, fax: 0208442 6545, e-mail: anthony@abate.org.uk) and Visiting Professor at University College London. His interests include treatment of personality disorder and the integration of psychotherapy and psychiatry. Professor Peter Tyrer is Head of the Department of Psychological Medicine at Imperial College, London, honorary consultant in rehabilitation psychiatry, Central North West London Mental Health NHS Trust and consultant to an assertive outreach team in Hammersmith and Fulham. He has been interested in personality disorders since 1965 . He is the Editor of the British Journal of Psychiatry, Past President of the European Branch of the International Society for the Study of Personality Disorders, Co-chair of the Section of Personality Disorders of the World Psychiatric Association and the Founder President of the British and Irish Group for the Study of Personality Disorders. 
Table 1 Summary of treatments used for personality disorder and the level at which they have been investigated

Type of treatment

Psychodynamic therapy

Cognitive-behavioural therapy

Dialectical behaviour therapy

Therapeutic community

Cognitive analytic therapy

Behaviour therapy

Nidotherapy
Main purpose of treatment

Evidence level ${ }^{1}$

To increase reflective capacity and emotional and interpersonal understanding

To alter dysfunctional core beliefs Initially, to reduce self-harm; eventually, to achieve transcendence To effect attitudinal and behavioural change

To achieve greater self-understanding

To improve maladaptive behaviour

To achieve better environmental adjustment thus minimising impact of disorder (Tyrer, 2002a) and it is commonly described as the difference between an explanatory trial, i.e. a trial in which treatments are compared under ideal (experimentally manipulated) conditions, and a pragmatic trial, in which the study is carried out under the conditions normally appertaining to ordinary practice. In the latter trial, possible confounders to the intervention may be present, and although they could be removed, to do so would create an artificial environment that would not allow the results to be transferred to ordinary practice.

Schwarz \& Lellouch (1967) showed that the results of explanatory and pragmatic trials could be very different even though the treatments under test were the same. As personality disorders commonly occur in conjunction with other disorders, there is a place for both in their evaluation. In evidence-based psychiatry these are sometimes described as trials of efficacy (explanatory) and effectiveness (pragmatic). Each has its advantages and disadvantages, but in general it is common to establish efficacy first under controlled conditions, before testing an intervention in conditions of ordinary practice.

Because of the formidable difficulties of meeting these requirements (Box 1), there has been a tendency for investigators to abandon them or at least to fulfil

\section{Box 1 Requirements for establishing an} effective treatment

- Efficacy in randomised controlled trial over control treatments when used for a pure form of the personality disorder

- Similar outcome in pragmatic randomised controlled trial

- Consistency across settings when used with appropriate treatment fidelity

- Maintenance of outcome over time (preferably more than 1 year) because of the long duration of personality disorder them only partially, and the literature on personality disorder, particularly with psychotherapeutic interventions, is often difficult to interpret (Bateman \& Fonagy, 2000).

\section{Choice of outcome measures}

Outcome measures have always been a problem in psychiatric disorders, but these difficulties become even more pronounced in the case of personality disorders because there are no agreed common outcomes. The wide range of those that have been measured are summarised in Table 2.

Personality disorders affect both the individual and society, and a range of outcomes can be measured to cover all these possibilities. Forensic psychiatrists and the general public may consider the effect on society to be the most important measure and insist that outcome for mentally disordered offenders is best measured by the frequency of re-offending. This is an easily measured, reliable statistic, although subject to social and judicial variation over time and distorted by a range of other factors such as the fact that patients who spend a long time in hospital or prison are not likely to reoffend. However, it does not record either symptomatic or personality changes, which are equally important, although they too may be subject to distortion. Changes in symptoms may be a consequence of change in mental state disorders quite independent of personality. In general, the interaction between personality disorder and Axis I disorder could result potentially in either an exaggeration of or an obscuring of a genuine treatment effect. Treatment might improve the mental illness but not the personality dysfunction or vice versa, and improvement in one may follow improvement in the other. Conversely, it is well known that mental illness can create the impression of abnormal personality, but that these characteristics change as the mental illness improves. Thus, any measured change in personality should be regarded in the first 
Table 2 Outcome measures used in efficacy studies of interventions for personality disorder

\begin{tabular}{|c|c|}
\hline Outcome & Forms of measurement \\
\hline Change in symptoms & $\begin{array}{l}\text { Standard rating scales } \\
\text { (e.g. for depression, } \\
\text { impulsiveness) }\end{array}$ \\
\hline Change in (social) function & $\begin{array}{l}\text { Rating scale measures of } \\
\text { disability and social function }\end{array}$ \\
\hline $\begin{array}{l}\text { Change in self-harm } \\
\text { behaviour }\end{array}$ & $\begin{array}{l}\text { Measures to record } \\
\text { episodes of self-harm }\end{array}$ \\
\hline Recidivism rates & $\begin{array}{l}\text { Standard records } \\
\text { of re-offending }\end{array}$ \\
\hline $\begin{array}{l}\text { Rates and duration of } \\
\text { psychiatric hospitalisation }\end{array}$ & $\begin{array}{l}\text { Obtained from standard } \\
\text { records (and usually costed } \\
\text { by nature of institution) }\end{array}$ \\
\hline Global outcome scales & $\begin{array}{l}\text { Standard scales of global } \\
\text { improvement }\end{array}$ \\
\hline Quality of life & $\begin{array}{l}\text { Standard quality } \\
\text { of life scales }\end{array}$ \\
\hline $\begin{array}{l}\text { Changes in personality } \\
\text { status }\end{array}$ & $\begin{array}{l}\text { Structured interview } \\
\text { schedules }\end{array}$ \\
\hline
\end{tabular}

Advantages and disadvantages

Useful to compare with other (symptomatic) conditions, but do not cover personality directly

Social function may be a good proxy measure of personality disorder, but is also influenced by factors independent of personality

Simple to record, but a problem to define, and only measure one part of personality disturbance (one of the core borderline features)

An easy measure of societal impact of antisocial behaviour but is not a direct measure of any form of personality disturbance

Relevant to costs of care (in-patient costs constitute by far the greatest proportion of total costs), but is not necessarily related to personality disorder

Relevant in that personality affects all modes of function so these are covered by global improvement, but unsatisfactory in that many other factors influence global outcome

The outcome measure with the greatest face validity, but most scales are not very sensitive to personality changes

These are the most obvious measures to record, but the short-term stability of personality is poor (see text)

instance as an artefact related to improvement or deterioration in mental state.

Because of these difficulties, there is a tendency to use global outcome measures such as the Global Assessment Scale (Endicott et al, 1976) to determine the degree of improvement in personality disorders in long-term follow-up studies, although a battery of measurements, covering different domains, is normally used in short-term treatment studies. Unfortunately, there is no standardised procedure for recording global outcome measures, but it is reasonable to take into account any, several, or all of the measures in Table 2, provided that there is a clear distinction between primary and secondary outcomes.

\section{Treatment evaluation}

In summarising each of the treatments, we have taken the nature of the evidence base, the choice of outcomes and the quality of studies into account and given a scores for efficacy and generalisability. These are shown in Table 3.

Many people with personality disorders have conditions with which they themselves are comfortable (i.e. they are egosyntonic) and have no wish to change. There is considerable variation between personality disorders in this respect. Those unwilling to have treatment can be described as type $\mathrm{R}$ (treatment-resisting), as opposed to type $\mathrm{S}$ (treatment-seeking); most of those with paranoid, antisocial and schizoid personality disorders come into the type R category, whereas those with borderline personality disorder are more often type $S$ (Tyrer et al, 2003a). This classification oversimplifies. Overt treatment seekers may be frightened of change, having gained a moderate level of psychological equilibrium over time through their interaction with services, or be seeking the gratification of an interactive relationship with medical services rather than looking for personal development. Others may avoid treatment but be desperate for help.

However, it reminds clinicians to assess motivation for change and explains why most of those who have personality disorder ( 3 out of 4 ) do not attend for treatment, as they belong to the type R group.

Our interpretation of the literature should be considered first in the context of personal bias (P.T. is especially interested in the role of cognitivebehavioural therapy and A.W.B. in psychodynamic 
Table 3 Efficacy and generalisability scores for psychological treatments of personality disorder

\begin{tabular}{|c|c|c|}
\hline Treatment & $\begin{array}{l}\text { Efficacy } \\
\text { score }^{1}\end{array}$ & $\begin{array}{c}\text { Generalisability } \\
\text { score }^{2}\end{array}$ \\
\hline Psychodynamic therapy & 2 & 2 \\
\hline Cognitive analytic the & 1 & 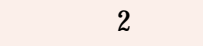 \\
\hline Cognitive therapy & 1 & 2 \\
\hline Dialectical behaviour therapy & 2 & 1 \\
\hline Therapeutic community & 2 & 1 \\
\hline \multicolumn{3}{|c|}{$\begin{array}{l}\text { 1. Efficacy scores: } 0 \text {, ineffective; } 1 \text {, unknown efficacy; } 2 \text {, } \\
\text { efficacy demonstrated in small studies }(<50 \text { patients) } \\
\text { only; } 3 \text {, efficacy demonstrated in large studies. } \\
\text { 2. Generalisability scores: } 0 \text {, highly selective and not } \\
\text { generalisable; } 1 \text {, selective and generalisability uncertain; } \\
\text { 2, some limited selection precluding full generalisability; } \\
\text { 3, typical patients with condition who are representative. }\end{array}$} \\
\hline
\end{tabular}

therapy for the treatment of personality disorder), and second in the light of a recent objective meta-analysis of the effectiveness of psychodynamic therapy and cognitive-behavioural therapy in the treatment of personality disorders. Leichsenring \& Leibing (2003) found that psychodynamic therapy yielded a large overall effect size of 1.46, with effect sizes of 1.08 for self-reported measures and 1.79 for observer-rated measures. This contrasts with cognitive-behavioural therapy, in which the corresponding values were 1.00, 1.20 and 0.87 respectively. In addition, the psychodynamic studies had a mean follow-up period of 1.5 years compared with only 13 weeks for the cognitivebehavioural therapy. However, the research literature is not extensive enough to draw firm conclusions from meta-analysis, and Leichsenring \& Leibing were able to include only 14 psychodynamic studies and 11 cognitive-behavioural therapy studies. In addition, the effect sizes cannot be compared directly because the studies differ, even within the same therapy group, in terms of therapy content, patient populations, outcome assessments and other variables.

\section{Psychological treatments Psychodynamic therapy}

Psychodynamic therapy has long been recommended, and has been modified to suit the particular problems associated with personality disorder. Most of the therapeutic interest in psychotherapy has related to borderline personality disorder (Higgitt \& Fonagy, 1992), which differs from almost all others in frequent help-seeking behaviour and evident wish to change.

There have been few published randomised trials of dynamic psychotherapy (Table 4), and only two have been widely noted. Winston et al (1991) showed no difference between short-term dynamic psychotherapy and brief adaptational psychotherapy, but both interventions were somewhat superior to a waiting-list control. This study specifically excluded patients with borderline and narcissistic features, although a later study including some patients with Cluster B disorders produced similar results (Winston et al, 1994).

\section{Mentalisation}

The most recent support for a psychoanalytically based approach has come from a randomised study examining the effectiveness of a psychoanalytically oriented partial hospitalisation programme with standard psychiatric care for patients with borderline personality disorder (Bateman \& Fonagy, 1999, 2001). This has now been fully manualised (Bateman \& Fonagy, 2004) as a mentalisation-based treatment. Treatment interventions are organised to increase the reflective or mentalising capacity of the patient in the context of group and individual therapy. Mentalisation entails making sense of the actions of oneself and others on the basis of intentional mental states such as desires, feelings and beliefs. It involves the recognition that what is in the mind is indeed in the mind and reflects knowledge of one's own and others' mental states as mental states. This capacity is enfeebled in borderline patients, and so group and individual therapy actively focuses on developing these patients' understanding and recognition of the feelings they evoke in others and the feelings evoked in them by others.

On all outcome measures there was significantly greater improvement in those allocated to psychotherapy. The improvements in symptoms and function were delayed by several months but were greatest by the end of treatment, at 18 months. In a follow-up study, which was done on an intentionto-treat basis, gains were maintained after a further 18 months (Bateman \& Fonagy, 2001), indicating that rehabilitative effects were stimulated during the treatment phase, although some treatment continued during the follow-up period. The treatment has also been found to be cost-effective (Bateman \& Fonagy, 2003), but as yet the active components of therapy remain unclear, especially because it was not possible to show that mentalisation had increased in the patients who showed the most gains. An outpatient version of mentalisation-based treatment is currently being evaluated for borderline and antisocial personality disorder in a further randomised controlled trial.

\section{Transference-focused psychotherapy}

Another manualised dynamic therapy, known as transference-focused psychotherapy, that gives promising results. The outcome of a randomised controlled trial comparing transference-focused psychotherapy, dialectical behaviour therapy (see 
Table 4 Trials of psychodyamic therapy in personality disorder

\begin{tabular}{|c|c|c|c|c|}
\hline Form of psychotherapy & $\begin{array}{l}\text { Personality } \\
\text { diagnosis }\end{array}$ & Reference & Type of study (n) & Main results \\
\hline $\begin{array}{l}\text { Psychodynamic with } \\
\text { partial hospitalisation } \\
\text { (day treatment) }\end{array}$ & Borderline & $\begin{array}{l}\text { Bateman } \\
\text { \& Fonagy } \\
(1999, \\
\text { 2001, 2003) }\end{array}$ & $\begin{array}{l}\text { Randomised } \\
\text { controlled trial } \\
(n=38)\end{array}$ & $\begin{array}{l}\text { Psychotherapy superior to treatment } \\
\text { as usual for self-harm, hospital } \\
\text { admissions, costs and symptoms, } \\
\text { but benefit delayed for } 6 \text { months }\end{array}$ \\
\hline $\begin{array}{l}\text { Brief psychodynamic } \\
\text { therapy (two types) }\end{array}$ & Borderline & $\begin{array}{l}\text { Winston } \\
\text { et al (1991) }\end{array}$ & $\begin{array}{l}\text { Randomised } \\
\text { controlled trial } \\
\text { ( } n=49, \text { including } 17 \\
\text { in waiting-list } \\
\text { control group) }\end{array}$ & $\begin{array}{l}\text { No significant difference between } \\
\text { treatments }\end{array}$ \\
\hline $\begin{array}{l}\text { Psychotherapy and } \\
\text { day hospital }\end{array}$ & $\begin{array}{l}\text { All types } \\
\text { (plus } \\
\text { affective } \\
\text { disorders) }\end{array}$ & $\begin{array}{l}\text { Piper et al } \\
\text { (1993) }\end{array}$ & $\begin{array}{l}\text { Controlled trial } \\
\text { (not randomised) } \\
(n=165)\end{array}$ & $\begin{array}{l}\text { No clear superiority of psycho- } \\
\text { therapy, but some indicators of } \\
\text { preference }\end{array}$ \\
\hline $\begin{array}{l}\text { Psychotherapy } \\
\text { preceded by } \\
\text { short in-patient care }\end{array}$ & ?Borderline & $\begin{array}{l}\text { Chiesa \& } \\
\text { Fonagy } \\
(2003)\end{array}$ & $\begin{array}{l}\text { Controlled trial } \\
\text { (not randomised) } \\
\text { with community } \\
\text { treatment and } \\
\text { therapeutic } \\
\text { community controls } \\
(n=135)\end{array}$ & $\begin{array}{l}\text { Psychotherapy preceded by in- } \\
\text { patient treatment yielded best } \\
\text { outcome, but results limited by fact } \\
\text { that only those living close to unit } \\
\text { could have this treatment }\end{array}$ \\
\hline
\end{tabular}

below) and supportive psychotherapy is not yet known, although its rationale has been described (Clarkin et al, 2004). In a cohort study (Clarkin et al, 2001), 23 women patients with borderline personality disorder were assessed at baseline and at the end of 12 months of treatment by means of diagnostic instruments, measures of suicidality, ratings of self-injurious behaviour and measures of medical and psychiatric service use. Compared with the year prior to treatment, the number of patients who made suicide attempts significantly decreased, as did the medical risk and severity of medical condition following self-injurious behaviour. In addition, patients during the treatment year had significantly fewer hospital admissions as well as number and days of psychiatric hospitalisation compared with the year before. The withdrawal rate was $19 \%$. Conference reports of a comparison study between patients treated with transference focused psychotherapy and a matched untreated control group confirm the benefits of treatment (Clarkin, 2002). Costs have not yet been examined.

\section{Community-based treatments}

Chiesa and co-workers studied the relative effectiveness of three psychodynamically oriented treatment models for a mixed group of personality disorders a long-term residential treatment using a therapeutic community approach; a briefer in-patient treatment followed by community-based dynamic therapy (step-down programme); and a general community psychiatric treatment. Initial results suggest that the brief in-patient therapeutic community treatment followed by out-patient dynamic therapy is more effective than both long-term residential therapeutic community treatment and general psychiatric treatment in the community on most measures, including self-harm, attempted suicide and readmission rates to general psychiatric wards, and is more costeffective (Chiesa et al, 2002). Follow-up at 36 months has confirmed that patients in the step-down programme continued to show significantly greater improvement than the in-patient group on social adjustment and global assessment of mental health. In addition they were found to mutilate themselves, attempt suicide and be readmitted significantly less at 24-month and 36-month follow-up (Chiesa \& Fonagy, 2003). However, the study was not a randomised trial and the groups were not strictly comparable.

In a related piece of work, in which personality status was not recorded, although disorder was likely to be present in a significant number of participants, Guthrie and her colleagues (Guthrie et al, 2001), in a randomised controlled trial, found that home-based psychodynamic/interpersonal psychotherapy was effective in reducing repetition of self-harm after 6 months.

\section{Group psychotherapy}

Non-controlled studies in which participants underwent day hospital stabilisation followed by out-patient dynamic group therapy indicate the value 
of using groups in borderline personality disorder (Wilberg et al, 1998). A randomised controlled trial by Marziali \& Monroe-Blum (1995) concentrated on group therapy alone without the additional milieu and social components of therapy; however, their therapy was not formally psychoanalytic but focused on relationship management. They found equivalent results between group and individual therapy, concluding that, on cost-effectiveness grounds, group therapy is the treatment of choice. Further studies are needed to confirm their findings, especially since the treatment offered was less structured than most other treatments and withdrawal rates were high.

\section{Cognitive analytic therapy}

Cognitive analytic therapy has been manualised for treatment of borderline personality disorder and many are enthusiastic about its effectiveness. There are indications that this treatment method may be of help to some patients (Ryle \& Golynkina, 2000), and in a small randomised trial (P. Richardson, personal communication, 2004) patients treated with cognitive analytic therapy showed significant improvement over time on a range of clinical measures. However, there was no difference between people receiving this therapy and those having other psychological treatments, so the effects may be non-specific. There was some indication that cognitive analytic therapy was judged more helpful than other psychological treatments by patients with borderline personality disorder, which might account for a lower but nonsignificant attrition rate in those undergoing this type of therapy. A formal randomised trial is now in progress comparing cognitive analytic therapy with 'best available standard care' for adolescent patients with borderline personality disorder in Victoria, Australia (Ryle, 2004).

\section{Cognitive therapy}

In cognitive therapy for personality disorders much greater emphasis is placed on changing core beliefs rather than dysfunctional thoughts and on maintaining a collaborative therapeutic alliance. Crisis intervention strategies are developed, training in self-help and self-monitoring skills is provided, and schema-focused conceptualisation is linked to behaviours that interfere with therapy, for example self-harm.

Davidson \& Tyrer (1996), in an open study, used cognitive therapy for the treatment of two Cluster $B$ personality disorders: antisocial and borderline personality disorders. They evaluated a brief (10session) cognitive therapy approach using singlecase methodology, which showed improvement in target problems (Table 5). Another small $(n=34)$, randomised controlled trial used brief cognitive therapy, linked to a manual incorporating elements of dialectical behaviour therapy, in the treatment of recurrent self-harm in those with Cluster B personality difficulties and disorders. Eighteen patients with a history of repeated self-harm and a parasuicide attempt in the preceding 12 months were randomly allocated to manual-assisted cognitive-behavioural therapy; 16 similar patients received treatment as usual. The rate of suicide acts was lower with the intervention therapy (median 0.17 per month, compared with 0.37 per month with usual treatment; $P=0.11$ ), and self-rated depressive symptoms also improved $(P=0.03)$. The treatment involved a mean of 2.7 sessions (each of 50 minutes duration), and the observed average cost of care was $46 \%$ less for the cognitive therapy group $(P=0.22)$.

This study led to a much larger study (Tyrer et al, 2003c), which probably comes closer to the model of effectiveness and generalisability than other studies.

Table 5 Trials of cognitive-behavioural therapy in personality disorder

\begin{tabular}{|c|c|c|c|c|}
\hline $\begin{array}{l}\text { Form of cognitive } \\
\text { therapy }\end{array}$ & $\begin{array}{l}\text { Personality } \\
\text { diagnosis }\end{array}$ & Reference & Type of study (n) & Main results \\
\hline $\begin{array}{l}\text { Beckian cognitive } \\
\text { therapy adapted } \\
\text { for personality } \\
\text { disorder }\end{array}$ & $\begin{array}{l}\text { Borderline } \\
\text { and antisocial }\end{array}$ & $\begin{array}{l}\text { Davidson \& } \\
\text { Tyrer (1996) }\end{array}$ & $\begin{array}{l}\text { Single-case } \\
\text { methodology } \\
\text { study }(n=10)\end{array}$ & $\begin{array}{l}\text { Slightly delayed improvement for } \\
\text { target symptoms }\end{array}$ \\
\hline $\begin{array}{l}\text { Brief manual-assisted } \\
\text { cognitive therapy }\end{array}$ & $\begin{array}{l}\text { Cluster B } \\
\text { personality } \\
\text { disturbance }\end{array}$ & $\begin{array}{l}\text { Evans et al } \\
(1999)\end{array}$ & $\begin{array}{l}\text { Randomised } \\
\text { controlled trial } \\
(n=34)\end{array}$ & $\begin{array}{l}\text { Trend towards less frequent self- } \\
\text { harm with MACT }(P=0.11) \text {, with } \\
\text { improvement in depression }(P<0.05) \\
\text { compared with ordinary treatment }\end{array}$ \\
\hline $\begin{array}{l}\text { Manual-assisted } \\
\text { cognitive therapy }\end{array}$ & $\begin{array}{l}\text { Recurrent } \\
\text { self-harm } \\
(42 \% \text { with } \\
\text { personality } \\
\text { disorder) }\end{array}$ & $\begin{array}{l}\text { Tyrer et al } \\
(2003 b, c) ; \\
\text { Byford et al } \\
\text { (2003) }\end{array}$ & $\begin{array}{l}\text { Randomised } \\
\text { controlled trial } \\
(n=480)\end{array}$ & $\begin{array}{l}\text { No difference between MACT and } \\
\text { treatment as usual, but MACT } \\
\text { more cost-effective }\end{array}$ \\
\hline
\end{tabular}


This was an extension of the manual-assisted cognitive-behavioural therapy study described earlier, with up to seven sessions of treatment offered to those with recurrent self-harm, $42 \%$ of whom had a personality disorder. It differed from other studies in being large $(n=480)$, being multicentred (five centres in Scotland and England), using ordinary therapists (trained in the approach) in the course of their normal work, and offering no special service for those in the trial. In particular, those who did not attend appointments were not visited at home, as this was not part of normal practice. The results were, in general, negative in terms of efficacy compared with treatment as usual (which included psychotherapy and problem-solving treatment). Only $60 \%$ of patients attended for face-to-face sessions of the intervention therapy, and for the primary outcome, proportion of patients repeating self-harm, $39 \%$ of those allocated to manual-assisted cognitive-behavioural therapy repeated self-harm compared with $46 \%$ allocated to treatment as usual $(P=0.20)$; there were seven suicides, five in the usual treatment group (Tyrer et al, 2003b). Frequency of selfharming behaviour was also reduced by $50 \%$ in the intervention therapy group compared with the usual treatment group, but there was great variation in episodes of self-harm (Tyrer et al, 2004). There was no difference in any of the secondary outcomes. However, important differences between some of these outcomes have been shown between therapists judged as competent after assessment of taped interviews in the study compared with those who were less competent (Davidson et al, 2004), and manual-assisted cognitive-behavioural therapy led to a cost saving of $£ 900$ per patient compared with usual treatment at 6 months, although this did not remain significant at 12 months (Byford et al, 2003). Interestingly, in borderline personality disorder manual-assisted cognitive-behavioural therapy increased total costs, in contrast to its effect in other personality disorders, and had less satisfactory results in reducing self-harm (Tyrer et al, 2004).

The overall evidence in favour of cognitivebehavioural therapy in treatment of personality disorder is therefore relatively slim, with much of it coming from one research group, but it has involved more patients than any other form of treatment Further research is required into personality disorder itself, and manual-assisted cognitivebehavioural therapy is currently being evaluated for borderline personality disorder in a three-centre randomised controlled trial.

\section{Dialectical behaviour therapy}

Dialectical behaviour therapy is a special adaptation of behaviour therapy. It is a manualised therapy (Linehan, 1993) which includes techniques at the level of behaviour (functional analysis), cognition (e.g. skills training) and support (empathy, teaching management of trauma). The aim of the therapy is first to control self-harm but then, more importantly, to promote change in the emotional dysregulation that is judged to be the core of the disorder (Robins, 2003). Dialectical behaviour therapy was originally used for the treatment of a group of repeatedly parasuicidal female patients with DSM-III-R borderline personality disorder (Linehan et al, 1991). The 44 female patients admitted to the trial had each made at least two suicide attempts in the previous 5 years, with one in the preceding 8 weeks. Twenty-two of them were assigned to dialectical behaviour therapy and 22 to the control condition.

Treatment with dialectical behaviour therapy for 1 year compared with treatment as usual led to a reduction in the number and severity of suicide attempts and decreased the frequency and length of in-patient admission. However, there were no between-group differences on measures of depression, hopelessness or reasons for living.

Follow-up was naturalistic, based on the proposition that the morbidity of this group precluded termination of therapy at the end of the experimental period. At 6-month follow-up, dialectical behaviour therapy patients continued to show less parasuicidal behaviour than controls, although at 1 year there was no between-group difference (Linehan et al, 1993). Although at 1 year the dialectical behaviour therapy patients had had fewer days in hospital, at the 6-month assessment there was no between-group difference (Linehan et al, 1993).

\section{Is its popularity justified?}

The widespread adoption of dialectical behaviour therapy is a tribute both to the energy and charisma of its founder, Marsha Linehan, and to the attractiveness of the treatment, with its combination of acceptance and change, skills training, excellent manualisation, and a climate of opinion that is willing and able to embrace this multifaceted approach (Swenson, 2000). It is not, however, justified by the strength of the evidence (Tyrer, $2002 b$ ) and conclusions about the long-term effectiveness of this therapy as a treatment for the personality itself are premature (Levendusky, 2000; Scheel, 2000; Turner, 2000). Since the original trial, handicapped by many methodological limitations, there has only been one randomised study that supports the findings unequivocally, that of Verheul et al (2003) (Table 6).

In the study by Verheul and co-workers, 58 Dutch women who met DSM-IV criteria for borderline personality disorder were randomly assigned to 


\begin{tabular}{|c|c|c|c|c|}
\hline Form of therapy & $\begin{array}{l}\text { Personality } \\
\text { diagnosis }\end{array}$ & Reference & $\begin{array}{l}\text { Type of study } \\
(n)\end{array}$ & Main results \\
\hline $\begin{array}{l}\text { Intensive (two group } \\
\text { and one individual } \\
\text { session per week) }\end{array}$ & $\begin{array}{l}\text { Borderline } \\
\text { (women } \\
\text { only) }\end{array}$ & $\begin{array}{l}\text { Linehan et al } \\
(1991)\end{array}$ & $\begin{array}{l}\text { Randomised } \\
\text { controlled trial } \\
(n=44)\end{array}$ & $\begin{array}{l}\text { Significant reduction in self-harm } \\
\text { and less hospitalisation in DBT group }\end{array}$ \\
\hline $\begin{array}{l}\text { Intensive group and } \\
\text { individual therapy } \\
\text { with specialist dialectical } \\
\text { behaviour therapists }\end{array}$ & $\begin{array}{l}\text { Borderline, } \\
\text { drug misuse }\end{array}$ & $\begin{array}{l}\text { Verheul et al } \\
\text { (2003) }\end{array}$ & $\begin{array}{l}\text { Randomised } \\
\text { controlled trial } \\
(n=58)\end{array}$ & $\begin{array}{l}\text { Better retention than TAU group } \\
\text { Reduction in self-harm } \\
\text { No effect on drug use }\end{array}$ \\
\hline
\end{tabular}

either 1 year of dialectical behaviour therapy or treatment as usual, i.e. ongoing treatment in the community. Participants were clinical referrals from both addiction treatment and psychiatric services. Efficacy was measured in terms of treatment retention, and course of high-risk suicidal, selfmutilating and otherwise self-damaging behaviours. Dialectical behaviour therapy resulted in better retention rates $(63 \%$ v. 23\%) and significantly greater reductions of self-mutilating behaviours and selfdamaging impulsive acts than treatment as usual, especially among those with histories of frequent self-mutilating behaviours. The study suggests dialectical behaviour therapy is superior to usual treatment in reducing self-mutilating and otherwise self-damaging impulsive behaviours in patients with borderline personality disorder; post hoc analyses suggested that those with more severe selfharming behaviour were helped most.

Other studies have been uncontrolled, too small to add any useful data (Koons et al, 2000) or have shown dialectical behaviour therapy to be no better than other active treatments such as the 12-step programme for alcohol dependence (Linehan et al, 2002). In addition, it is not clear which elements of dialectical behaviour therapy (psychotherapy, skills training, telephone consultation, therapist consultation team) make this treatment method effective. Two studies investigated the process of change in dialectical behaviour therapy by focusing on the possible influence of validation (Shearin \& Linehan, 1992; Linehan \& Heard, 1993; Linehan et al, 2002), but results are inconclusive. What we know thus far is that adding a dialectical behaviour therapy skills-training group to ongoing out-patient individual psychotherapy does not seem to enhance treatment outcomes. Given that dialectical behaviour therapy is described as primarily a skills-training approach (Koerner \& Linehan, 1992), this finding indicates that the central skills-training component of dialectical behaviour therapy may not be of primary importance. The policy of not admitting patients to hospital, except for a bare minimum period, has also been challenged, as time spent in a structured in-patient setting has been used to apparently good effect (Bohus et al, 2004). There are also concerns that the rigidity of the programme leads to a greater proportion of people withdrawing from care, and about primary its preoccupation with the treatment of women.

For this reason we do not give dialectical behaviour therapy a greater efficacy rating than other treatments; its benefits are mainly confined to reduction of self-harm episodes.

\section{Therapeutic community treatments}

A therapeutic community may be defined as an intensive form of treatment in which the environmental setting becomes the core therapy, where behaviour can be challenged and modified, essentially through group interaction and interpersonal understanding. Although such communities have been in existence in the UK and Denmark for over 50 years, they have only recently been subjected to direct controlled evaluation. The treatments and patient populations treated are so varied that the results are difficult to interpret, but the consensus mainly advanced by proponents of the treatment - is generally favourable. A systematic review of the literature by Lees et al (1999) concluded that therapeutic communities, particularly the so-called 'concept' communities in the USA, were effective, but the positive effects were found primarily in people who were substance misusers living in secure settings in which there was a considerable degree of coercion and no emphasis was placed on the treatment of personality disorder.

The more common version in Europe is the democratic therapeutic community, and no randomised trial has been carried out in this setting. However, Dolan and colleagues at the Henderson Hospital, in a creative attempt to find an appropriate control group, used a non-admitted comparison sample to assess the effectiveness of treatment on 
core symptoms (Dolan et al, 1997). A total of 137 patients were studied, of whom 70 were admitted and 67 not admitted (either for clinical or for financial reasons). However, this was not a strict comparison group, because less than 1 in 7 of those considered for the Henderson Hospital complete their treatment (Rutter \& Tyrer, 2003). There was significantly greater reduction in core features of personality disorder on the Borderline Syndrome Index in the treated group than in the non-admitted group. However, using this index as a primary outcome measure is inadequate because significant state dependent fluctuations of core features of personality disorder may occur over time, and in a UK study this index has been found to lack validity and to be susceptible to distortion from current symptoms (Marlowe et al, 1996).

Further work has suggested that therapeutic community treatment may show cost savings over treatment in general psychiatric services primarily through reducing the need for hospital admission (Davies et al, 1999).

Extended hospital admission theoretically may engender pathological dependency and regression (Linehan, 1987), although there is little evidence for this. In a prospective study of 216 patients with severe personality disorder treated at the Menninger Clinic in the USA for variable lengths of time in two psychoanalytically oriented in-patient units, Gabbard et al (2000) found positive change at discharge and at 1-year follow-up, with no evidence of deleterious effects due to regression and dependency. Nevertheless, the classic paper by Main (1957) should act as a reminder that regression and countertransference may pose considerable difficulties for teams treating patients intensively.

As there are now many more treatments available for the treatment of personality disorder, therapeutic communities need to come into the frame of comparison studies. Further research should be undertaken (Haigh, 2002), but proponents will need to adopt acceptable experimental designs if therapeutic communities are to compete with other treatments.

\section{Conclusions}

Despite these somewhat cautionary views, it is important to note that, for the first time in the history of personality disorder, people are regarding the condition as potentially treatable. It is likely that effective treatments are going to be found in the course of the next two decades and, if this turns out to be the case, it will help greatly in removing the pejorative label that currently is attached to personality disorder.

\section{References}

Bateman, A. \& Fonagy, P. (1999) The effectiveness of partial hospitalization in the treatment of borderline personality disorder - a randomised controlled trial. American Journal of Psychiatry, 156, 1563-1569.

Bateman, A. \& Fonagy, P. (2000) Effectiveness of psychotherapeutic treatment of personality disorder. British Journal of Psychiatry, 177, 138-143.

Bateman, A. \& Fonagy, P. (2001) Treatment of borderline personality disorder with psychoanalytically oriented partial hospitalisation: an 18-month follow-up. American Journal of Psychiatry, 158, 36-42.

Bateman, A. \& Fonagy, P. (2003) Health service utilisation costs for borderline personality disorder patients treated with psychoanalytically oriented partial hospitalisation versus general psychiatric care. American Journal of Psychiatry, 160, 169-171.

Bateman, A. \& Fonagy, P. (2004) Psychotherapy for Borderline Personality Disorder: Mentalisation Based Treatment. Oxford: Oxford University Press.

Bateman, A. W. \& Tyrer, P. (2004) Organisation of services for personality disorder. Advances in Psychiatric Treatment, 10, in press.

Bohus, M., Haaf, B., Simms, T., et al (2004) Effectiveness of inpatient dialectical behavioural therapy for borderline personality disorder: a controlled trial. Behaviour Research and Therapy, 42, 487-499.

Byford, S., Knapp, M., Greenshields, J., et al (2003) Costeffectiveness of brief cognitive behaviour therapy versus treatment as usual in recurrent deliberate self-harm: a decision-making approach. Psychological Medicine, 33, 977986.

Campbell, M., Fitzpatrick, R., Haines, A., et al (2000) A framework for the design and evaluation of complex interventions to improve health. BMJ, 321, 694-696.

Chiesa, M. \& Fonagy, P. (2003) Psychosocial treatment for severe personality disorder: 36-month follow-up. British Journal of Psychiatry, 183, 356-362.

Chiesa, M., Fonagy, P., Holmes, J., et al (2002) Health Service use costs by personality disorder following specialist and non-specialist treatment: a comparative study. Journal of Personality Disorders, 16, 160-173.

Clark, L. A., Vittengl, J., Kraft, D., et al (2003) Separating personality traits from states to predict depression. Journal of Personality Disorders, 17, 152-172.

Clarkin, J. F. (2002) Personality disorders: neurobiology and psychotherapy. Abstracts of 5th ISSPD European Congress on Personality Disorders. Munich: ISSPD.

Clarkin, J. F., Foelsch, P., Levy, K., et al (2001) The development of a psychodynamic treatment for patients with borderline personality disorder: a preliminary study of behavioural change. Journal of Personality Disorders, 15, 487-495.

Clarkin, J. F., Levy, K. N., Lenzenweger, M. F., et al (2004) The Personality Disorders Institute/Borderline Personality Disorder Research Foundation randomised controlled trial for borderline personality disorder: rationale, methods, and patient characteristics. Journal of Personality Disorders, 18, 52-72.

Davidson, K. \& Tyrer, P. (1996) Cognitive therapy for antisocial and borderline personality disorders: single case study series. British Journal of Clinical Psychology, 35, 413429.

Davidson, K., Scott, J., Schmidt, U., et al (2004) Therapist competence and clinical outcome in the prevention of parasuicide by manual assisted cognitive behaviour therapy trial: the POPMACT study. Psychological Medicine, in press.

Davies, S., Campling, P. \& Ryan, K. (1999) Therapeutic community provision at regional and district levels. Psychiatric Bulletin, 23, 79-83.

Dolan, B., Warren, F. \& Norton, K. (1997) Change in borderline symptoms one year after therapeutic community treatment for severe personality disorder. British Journal of Psychiatry, 171, 272-279. 
Endicott, J., Spitzer, R. L., Fleiss, J. L. et al (1976) The global assessment scale: a procedure for measuring overall severity of psychiatric disturbance. Archives of General Psychiatry, 33, 766-771.

Evans, K., Tyrer, P., Catalan, J., et al (1999) Manual-assisted cognitive-behavioural therapy (MACT): a randomised controlled trial of a brief intervention with bibliotherapy in the treatment of recurrent deliberate self-harm. Psychological Medicine, 29, 19-25.

Gabbard, G., Coyne, L., Allen, J., et al (2000) Evaluation of intensive in-patient treatment of patients with severe personality disorders. Psychiatric Services, 51, 893-898.

Guthrie, E., Kapur, N., Mackway-Jones, K., et al (2001) Randomised controlled trial of brief psychological intervention after deliberate self-poisoning. BMJ, 323, 135137.

Haigh, R. (2002) Therapeutic community research: past, present and future. Psychiatric Bulletin, 26, 68-70.

Higgitt, A. \& Fonagy, P. (1992) Psychotherapy in borderline and narcissistic personality disorder. British Journal of Psychiatry, 161, 23-24.

Koerner, K. \& Linehan, M. M. (1992) Integrative therapy for borderline personality disorder: dialectical behaviour therapy. In Handbook of Psychotherapy Integration (ed. J. C. Norcross), pp. 433-459. New York: Basic Books.

Koons, C., Robins, C. \& Tweed, J. (2000) Efficacy of dialectical behavior therapy in women veterans with borderline personality disorder. Behavior Therapy, 32, 371-390.

Lees, J., Manning, N. \& Rawlings, B. (1999) Therapeutic Community Effectiveness. A Systematic International Review of Therapeutic Community Treatment for People with Personality Disorders and Mentally Disordered Offenders (CRD Report 17). York: NHS Centre for Reviews and Dissemination, University of York.

Leichsenring, F. \& Leibing, E. (2003) The effectiveness of psychodynamic therapy and cognitive behavior therapy in the treatment of personality disorders: a meta-analysis. American Journal of Psychiatry, 160, 1223-1232.

Levendusky, P. (2000) Dialectical behavior therapy: so far so soon. Clinical Psychology Science and Practice, 7, 99100.

Linehan, M. M. (1987) Dialectical behavioural therapy: a cognitive behavioural approach to parasuicide. Journal of Personality Disorders, 1, 328-333.

Linehan, M. M. (1993) The Skills Training Manual for Treating Borderline Personality Disorder. New York: Guilford Press.

Linehan, M. \& Heard, H. (1993) Impact of treatment accessibility on clinical course of parasuicidal patients: reply. Archives of General Psychiatry, 50, 157-158.

Linehan, M. M., Armstrong, H., Suarez, A., et al (1991) Cognitive-behavioural treatment of chronically parasuicidal borderline patients. Archives of General Psychiatry, 48, 1060-1064.

Linehan, M. M., Heard, H. L. \& Armstrong, H. E. (1993) Naturalistic follow-up of a behavioral treatment for chronically parasuicidal borderline patients. Archives of General Psychiatry, 50, 971-974.

Linehan, M., Dimeff, L., Reynolds, S., et al (2002) Dialectical behavior therapy versus comprehensive validation therapy plus 12-step for the treatment of opioid dependent women meeting criteria for borderline personality disorder. Drug and Alcohol Dependence, 67, 13-26.

Main, T. (1957) The ailment. British Journal of Medical Psychology, 30, 129-145.

Marlowe, M. J., O’Neill-Byrne, K., Lowe-Ponsford, F., et al (1996) The borderline syndrome index: a validation study using the personality assessment schedule. British Journal of Psychiatry, 168, 72-75.

Marziali, E. \& Monroe-Blum, H. (1995) An interpersonal approach to group psychotherapy with borderline personality disorder. Journal of Personality Disorders, 9, 179189.

Piper, W. E., Rosie, J. S., Azim, H. F., et al (1993) A randomised trial of psychiatric day treatment for patients with affective and personality disorders. Hospital and Community Psychiatry, 44, 757-763.
Robins, C. (2003) Dialectical behavior therapy for borderline personality disorder. Psychiatric Annals, 32, 608-616.

Rutter, D. \& Tyrer, P. (2003) The value of therapeutic communities in the treatment of personality disorder: a suitable place for treatment? Journal of Psychiatric Practice, 9, 291-302.

Ryle, A. (2004) The contribution of cognitive analytic therapy to the treatment of borderline personality disorder. Journal of Personality Disorders, 18, 3-35.

Ryle, A. \& Golynkina, K. (2000) Effectiveness of time-limited cognitive analytic therapy of borderline personality disorder: factors associated with outcome. British Journal of Medical Psychology, 73, 197-210.

Scheel, K. (2000) The empirical basis of dialectical behavior therapy: summary, critique, and implications. Clinical Psychology Science and Practice, 7, 68-86.

Schwarz, D. \& Lellouch, J. (1967) Explanatory and pragmatic attitudes in therapeutic trials. Journal of Chronic Diseases, 20, 637-648.

Shearin, E. \& Linehan, M. M. (1992) Patient-therapist ratings and relationship to progress in dialectical behaviour therapy for borderline personality disorder. Behaviour Therapy, 23, 730-741

Swenson, C. (2000) How can we account for DBT's widespread popularity? Clinical Psychology Science and Practice, 7, 87-91.

Turner, R. (2000) Understanding dialectical behaviour therapy. Clinical Psychology Science and Practice, 7, 9598.

Tyrer, P. (2002a) Nidotherapy: a new approach to the treatment of personality disorder. Acta Psychiatrica Scandinavica, 105, 469-472.

Tyrer, P. (2002b) Practice guideline for the treatment of borderline personality disorder: a bridge too far? Journal of Personality Disorders, 16, 113-118.

Tyrer, P. \& Bateman, A. W. (2004) Drug treatments for personality disorder. Advances in Psychiatric Treatment, 10, 389-398.

Tyrer, P., Gunderson, J., Lyons, M., et al (1997) Extent of comorbidity between mental state and personality disorders. Journal of Personality Disorders, 11, 242-259.

Tyrer, P., Mitchard, S. \& Methuen, C. (2003a) Treatmentrejecting and treatment-seeking personality disorders: type $\mathrm{R}$ and type S. Journal of Personality Disorders, 17, 265270

Tyrer, P., Jones, V. \& Thompson, S. (2003b) Service variation in baseline variables and prediction of risk in a randomised controlled trial of psychological treatment in repeated parasuicide: the POPMACT study. International Journal of Social Psychiatry, 49, 58-69.

Tyrer, P., Thompson, S., Schmidt, U., et al (2003c) Randomized controlled trial of brief cognitive behaviour therapy versus treatment as usual in recurrent deliberate self-harm: the POPMACT study. Psychological Medicine, 33, 969-976.

Tyrer, P., Tom, B., Byford, S., et al (2004) Differential effects of manual assisted cognitive behaviour therapy in the treatment of recurrent deliberate self-harm and personality disturbance: the POPMACT study. Journal of Personality Disorders, 18, 102-116.

Verheul, R., Van Den Bosch, L. M., Koeter, M. W., et al (2003) Dialectical behaviour therapy for women with borderline personality disorder: 12 -month, randomised clinical trial in The Netherlands. British Journal of Psychiatry, 182, 135140

Wilberg, T., Friis, S., Karterud, S., et al (1998) Outpatient group psychotherapy: a valuable continuation treatment for patients with borderline personality disorder treated in a day hospital? A 3-year follow-up study. Nordic Journal of Psychiatry, 52, 213-222.

Winston, A., Pollack, J., McCullough, L., et al (1991) Brief psychotherapy of personality disorders. Journal of Nervous and Mental Disease, 179, 188-193.

Winston, A., Laikin, M., Pollack, J., et al (1994) Short-term dynamic psychotherapy of personality disorders. American Journal of Psychiatry, 15, 190-194. 


\section{MCQs}

1 Assessing efficacy of psychotherapeutic treatment for personality disorder is complicated by:

a low comorbidity with other disorders

$\mathrm{b}$ requirement for a long follow-up

c lack of agreement on outcome measures

d the fluctuating nature of this disorder over time

e problems of finding patients.

2 When considering efficacy and generalisability of treatments for personality disorder:

a cognitive-behavioural therapy has the best evidence for both

b dynamic therapy shows no evidence of generalisability

c dialectical behaviour therapy is the treatment of choice

d therapeutic community approaches are easily generalisable

e cognitive analytic therapy shows excellent efficacy in borderline personality disorder.

3 Psychodynamic therapy for personality disorder:

a is too complex to manualise

b may be effective in reducing self-harm c is commonly associated with a high drop-out rate

$\mathrm{d}$ is better than standard psychiatric care

e can only be given by highly trained practitioners.

4 Cognitive therapy for personality disorder:

a is more effective than any other psychotherapy

$\mathrm{b}$ is no better than standard psychiatric care in patients who harm themselves

c is simply a watered-down version of dialectical behaviour therapy

d focuses on automatic thoughts

e shows overlap with psychodynamic therapy in its use of the therapeutic relationship.

5 Dialectical behaviour therapy for personality disorder:

a has been shown to be effective in paranoid personality disorder

b requires skills training if it is to be effective

c has widespread acceptance because of frequent replication of good outcomes

d may be used effectively on in-patients

e has limited effect on drug misuse. 